\title{
The Bologna process: a study about teachers' perception of their new role and its consequences
}

\section{Lagoa-Varela, Dolores a ; Alvarez García, Begoña ${ }^{a}$ and Boedo Vilabella, Lucía ${ }^{\text {a }}$}

${ }^{a}$ Financial Economics and Accounting Department, Facultad de Economía y Empresa, Campus de Elviña, s/n. Universidad de A Coruña. 15071, A Coruña, Spain.

\begin{abstract}
The present paper analyzes the implications of the Bologna Process concerning two specific issues: the perception of teachers about their new role and its consequences, and to what extent the adaptation to Bologna has brought about major or minor changes in the teaching methodology. In addition, we examine whether differences of opinion arise depending on the distinct personal and professional characteristics of each teacher. The conclusions of the paper note the benefits and drawbacks encountered that can help in setting out future goals.

The results reveal that most of the methodological changes undergone by the teachers stem more from the new profile of their students than from mandatory regulations. There is a unanimous opinion that the time and effort dedicated to teaching is now notably greater and that it is necessary to develop a rigorous system of teaching evaluation. In addition, we observe two clear aspects: on the one hand, staff with longer experience has carried out more changes and uses new technologies to a greater extent and, on the other hand, the use and promotion of English in class is still a crucial issue. This paper focuses on Economics and Business teachers, but most results apply to other degrees.
\end{abstract}

Keywords: Transformed Role of Teachers; European Higher Education Area (EHEA); economics education; university teaching; teaching methods 


\section{Introduction}

University in general, and in Spain in particular, has undergone a significant change in recent years. We have witnessed important social, economic, and technological transformations which have lead us to a completely different scenario. In this context, the development of the European Higher Education Area (EHEA) brought about specific and regulated changes in degrees, affecting both the organization of the institutions and the formal structure of the courses and, most importantly, a new approach to teaching and to learning.

All this process has generated great controversy both among teachers and students and, despite education always being in continual evolution, it seems that there is a consensus that now is the moment to evaluate not only what has been done in Spain but also the exact manner in which it has been done. The concern is not to continue making alterations but to reflect on those already made, to know what consequences have emerged from the transformation process and detect problems before setting out future goals.

In recent years papers on this subject have been published. Many of them are reflections concerning diverse aspects of the EHEA (Rabinet 2008; Fernández, Carballo and Galán 2015), others are descriptive studies analyzing a specific new teaching methodology (Cabello and Antón 2005; Trilling and Fadel 2009, Macfarlane 2011) and there are also numerous papers based on students opinions or attitudes (Linblom-Yläne, Trigwell; Negui and Ashwin 2007; Fernandéz-Sainz, García-Merino and Urionabarrenetxea 2015). However, studies on teaching staff questionnaires are scarcer. The information provided by this type of work is very valuable since it will allow us to know lecturer's opinions about the negative and positive aspects of this process. Moreover it is important to have a sufficient number of this type of research so that we can draw clear and verified conclusions that can be considered in future reforms in higher education.

Hence, we present a new study towards this objective. By means of a survey of University teachers in the fields of Economics and Business, we can analyze their perception of this process in these key ways: the new methodologies which have been implemented and the reasons for the change; the extent to which this whole process has modified their way of working and, finally the benefits and drawbacks encountered. Moreover, we examine whether differences of opinion arise in terms of the distinct personal and professional characteristics of each teacher.

This type of study is not easy to conduct on the University system as a whole. We have chosen Economics and Business university studies for two reasons. First, the application of most of the contents is practically immediate (financial products, business management, etc.) so that changes in methodology have been rather abrupt. Second, these are degrees with a high demand profile and a high rate of employability. Nevertheless, even with these particular features, we found that many of the conclusions can be generalized to other degrees. 


\section{Methodology}

Participants were 370 teachers (181 females and 189 males) from Spanish public and private universities with degrees in Economics and Business. In order to achieve the objectives stated, a survey with nineteen questions was developed according to a five-point Likert scale, where Strongly disagree $=1$, Disagree $=2$, Somewhat agree $=3$, Agree $=4$ and Strongly agree $=5$. This questionnaire was organized in two parts. Eight questions were included in the first part with the idea of assessing to what extent the Spanish university teacher is assuming a new role in the classroom and eleven questions were included in the second part with the objective of knowing to what extent these teachers have articulated changes in the development of their lectures. The selection of the questions is based on what we saw in other papers, the information we want to achieve and on our own personal experience and perceptions in relation to the most important recent changes.

Information on this study and the hyperlink giving access to the questionnaire (which was available on the Web) was sent to all deans and directors of Spanish universities with degrees in Economics and Business, who then circulated it to all the teaching staff.

\section{Findings and discussion}

\subsection{Teacher evaluation of the change process}

In the first part of the questionnaire eight items referring to the study of teacher perceptions about change are raised and it is worth noting the high response rate in most of them (Table $1)$.

Table 1. Summary results about the perception of teaching changes

\begin{tabular}{|c|c|c|c|c|c|c|}
\hline Assertions & $\mathrm{N}$ & $\%$ & Mean & Median & Mode & $\begin{array}{l}\text { Standard } \\
\text { Deviation }\end{array}$ \\
\hline 1. In recent years I have considerably changed my teaching methodology. & 370 & $100 \%$ & 3.6 & 4 & 4 & 0.947 \\
\hline $\begin{array}{l}\text { 2. Changes in teaching methodology have been made on my own } \\
\text { initiative in order to adapt to the student profile. }\end{array}$ & 366 & $99 \%$ & 3.83 & 4 & 4 & 1.028 \\
\hline $\begin{array}{l}\text { 3. Changes in teaching methodology have only been given by the } \\
\text { implementation of new degrees. }\end{array}$ & 367 & $99 \%$ & 2.97 & 3 & 4 & 1.249 \\
\hline $\begin{array}{l}\text { 4. The new teacher role requires a greater dedication to teaching than } \\
\text { traditional teaching. }\end{array}$ & 368 & $99 \%$ & 4.54 & 5 & 5 & 0.787 \\
\hline $\begin{array}{l}\text { 5. I believe it is necessary to assume specific training to take on the new } \\
\text { role. }\end{array}$ & 367 & $99 \%$ & 3.56 & 4 & 4 & 1.227 \\
\hline $\begin{array}{l}\text { 6. The lack of time and resources are real obstacles to obtaining better } \\
\text { teaching development. }\end{array}$ & 367 & $99 \%$ & 3.75 & 4 & 5 & 1.171 \\
\hline $\begin{array}{l}\text { 7. Research assesment in university teaching prevents me from devoting } \\
\text { time to teaching practice/work. }\end{array}$ & 360 & $97 \%$ & 3.65 & 4 & 5 & 1.264 \\
\hline $\begin{array}{l}\text { 8. The definition of a reliable and rigorous system of teaching and } \\
\text { traininig quality assesment for he university teachers should be } \\
\text { necessary. }\end{array}$ & 363 & $98 \%$ & 4.47 & 5 & 5 & 0.853 \\
\hline
\end{tabular}


The item which generates a greater consensus, in line with the findings of Ariza et al (2014) and Quevedo-Blasco et al (2015), is the one related to the greater teaching dedication.required by the new role of the teacher in relation to the dedication formerly required in traditional teaching (item 4 ). This question is followed closely by the fact that there is a general feeling among teachers consulted regarding the need to define a reliable and rigorous system of teaching quality assessment (item 8 , in the same way as an assessment of their research activity is made). This matter is also stated by teachers in Quevedo-Blasco et al. (2015), indicating that the teacher evaluation methods are inefficient.

From the answers to questions 2 and 3 we deduce that changes made in teaching methodology have not only been due to the implementation of the new degrees, but rather due to teachers' commitment to connect with students much more. In fact, $69 \%$ of teachers state that they have made changes in the teaching methodology on their own initiative and not by external demands.

Regarding the need to assume specific training to take on the new role, $57 \%$ of teachers agree with this assertion. These results differ somewhat from those obtained by Ariza et al. (2014) and Quevedo-Blasco et al. (2015). In these papers, 60.5\% and 50.8\% of teachers, respectively, consider that they have adequate training to teach in the EHEA context, while $32.8 \%$ and $35.8 \%$, respectively, maintained that they could improve and would need to receive more training.

For the analysis of the issues taking into account the personal and professional characteristics of the interviewed subjects, we use contingency tables in order to show evidence of significance between the answers and the different characteristics of the teachers. Table 2 provides the results of contrast, highlighting in bold those cases where the null hypothesis is rejected and there is therefore significant association (corresponding to higher values of the statistical chi-square and p-values taking a value less than 0.05 ). 
Table 2. Pearson Chi-square test.

Analysis of teacher's perception taking into account the teacher profile.

QUESTION NUMBER

\begin{tabular}{|c|c|c|c|c|c|c|c|c|c|}
\hline VARIABLE & 1 & 2 & 3 & 4 & 5 & 6 & 7 & 8 & \\
\hline \multirow{2}{*}{ Gender } & 8.191 & 2.648 & 10.824 & 14.173 & 12.029 & 5.095 & 7.503 & 1.925 & Value \\
\hline & 0.042 & 0.449 & 0.013 & 0.003 & 0.007 & 0.165 & 0.057 & 0.588 & Sig. \\
\hline \multirow{2}{*}{$\begin{array}{l}\text { Employment } \\
\text { Situation }\end{array}$} & 14.822 & 31.221 & 16.982 & 5.053 & 8.332 & 14.760 & 11.512 & 5.070 & Value \\
\hline & 0.251 & 0.002 & 0.152 & 0.282 & 0.759 & 0.255 & 0.486 & 0.535 & Sig. \\
\hline \multirow{2}{*}{$\begin{array}{c}\text { Professional } \\
\text { Status }\end{array}$} & 22.069 & 29.873 & 18.311 & 22.035 & 25.422 & 37.086 & 32.281 & 15.979 & Value \\
\hline & 0.229 & 0.039 & 0.107 & 0.037 & 0.114 & 0.005 & 0.015 & 0.594 & Sig. \\
\hline \multirow{2}{*}{$\begin{array}{c}\text { Teaching } \\
\text { Experience }\end{array}$} & 25.461 & 16.078 & 11.899 & 9.519 & 12.154 & 7.051 & 19.843 & 16.856 & Value \\
\hline & 0.013 & 0.188 & 0.454 & 0.658 & 0.433 & 0.854 & 0.071 & 0.155 & Sig. \\
\hline \multirow{2}{*}{$\begin{array}{c}\text { Public/Private } \\
\text { University } \\
\text { Institution } \\
\end{array}$} & 6.905 & 3.618 & 2.082 & 0.387 & 2.507 & 0.565 & 0.376 & 1.724 & Value \\
\hline & 0.075 & 0.306 & 0.556 & 0.943 & 0.474 & 0.904 & 0.945 & 0.632 & Sig. \\
\hline \multirow{2}{*}{ Subject Area } & 16.033 & 17.098 & 16.142 & 4.844 & 25.366 & 7.539 & 20.872 & 23.821 & Value \\
\hline & 0.381 & 0.313 & 0.373 & 0.774 & 0.045 & 0.941 & 0.141 & 0.068 & Sig. \\
\hline
\end{tabular}

Once it is known that a significant association exists between two nominal variables, the corrected standardized residuals ${ }^{1}$ are used to accurately interpret the meaning of the detected association (when interpreting residuals focus must be placed on those presenting absolute values larger than 2 , as these are the ones providing evidence of relationship).

The results reveal that teachers with less experience claim they have undertaken a lesser degree of change in their teaching methodology than teachers with experience between 10 and 20 years. With respect to the labor situation, we also find that teachers who are civil servants, facing the permanent staff, are the ones who have expressed greater agreement with item 2 (changes in teaching methodology have been carried out on my own initiative in order to adapt to the student profile). On the other hand, it can be stated that these are mainly teachers who have "junior" profiles (Assistants and Temporary), who mostly believe that research assessment as well as the lack of time and resources, are real obstacles to performing a better development of teaching.

Considering the gender variable, it can be observed that men agree less than women with items 3, 4 and 5. Females request more than males specific training in order to take on a new role which they believe requires more dedication than traditional teaching. They also confessed to have made changes in teaching methodology mainly due to the implementation of Degrees. Considering the area of knowledge, a different perception regarding the need for training to assume the new role can be detected.

${ }^{1}$ Standardized residuals are available upon request, but they have not been shown due to space limitations. 


\subsection{Specific implications for Teaching Methodology}

In the second part of the survey eleven items referring to changes in teaching conducted by university lecturers of Economics and Business were included. Our findings show that the teachers interviewed have modified their teaching methods significantly, the material for students work (item 6) and the use of computers and audiovisual resources (item 9), being the items acquiring a higher score (see table 3). In addition, there is unanimous agreement which indicates that now content matters as much as the procedure used to teach (item 8), which is a very important aspect to keep in mind when considering training courses for university teachers.

Our results also show that the use and promotion of a foreign language in the classroom (item 10) is still a pending issue in higher education, confirming the results obtained by Cavero et al. (2014), who observed the low presence of subjects linked to instrumental generic competences, like languages, on the European level Business Administration (BA) degrees (see Table 3).

Table 3. Summary results about the perception of implementation teaching changes.

\begin{tabular}{|c|c|c|c|c|c|c|}
\hline Assertions & $\mathrm{N}$ & $\%$ & Mean & Median & Mode & $\begin{array}{l}\text { Standard } \\
\text { Deviation }\end{array}$ \\
\hline 1. My lectures are increasingly more interactive. & 368 & $99 \%$ & 3.98 & 4 & 4 & 0.909 \\
\hline 2. I look for greater involvement by students. & 368 & $99 \%$ & 4.31 & 4 & 5 & 0.755 \\
\hline 3. I encourage the student to work in a more independent way. & 368 & $99 \%$ & 4.15 & 4 & 4 & 0.801 \\
\hline $\begin{array}{l}\text { 4. I plan and prepare the daily class work to make classes more } \\
\text { participatory. }\end{array}$ & 364 & $98 \%$ & 4.11 & 4 & 4 & 0.779 \\
\hline $\begin{array}{l}\text { 5. I prepare topical is sues by adapting them to the topic of the } \\
\text { classes. }\end{array}$ & 368 & $99 \%$ & 4.23 & 4 & 4 & 0.832 \\
\hline $\begin{array}{l}\text { 6. I prepare material for students work (problem solving. summary } \\
\text { guides. activities to develop.....) }\end{array}$ & 368 & $99 \%$ & 4.4 & 5 & 5 & 0.840 \\
\hline 7. I plan and organize debates on some issues. & 368 & $99 \%$ & 3.45 & 4 & 4 & 11.589 \\
\hline $\begin{array}{l}\text { 8.In the new role of the university teacher. not only content } \\
\text { ("what to teach") is important. but also method ("how to teach"). }\end{array}$ & 364 & $98 \%$ & 4.45 & 5 & 5 & 0.829 \\
\hline $\begin{array}{l}\text { 9. Frequently I use computers and audiovisual resources in the } \\
\text { classroom. }\end{array}$ & 368 & $99 \%$ & 4.36 & 5 & 5 & 0.970 \\
\hline $\begin{array}{l}\text { 10. I promote the use of a foreign language in my classroom (with } \\
\text { readings. explanations. et...) }\end{array}$ & 370 & $100 \%$ & 2.81 & 3 & 2 & 13.385 \\
\hline 11. I correct. guide and mentor several student projects. & 367 & $99 \%$ & 4.08 & 4 & 5 & 10.059 \\
\hline
\end{tabular}

Due to the existence of high correlations between the answers (to the eleven items) found in a preliminary analysis of the variables, it was considered appropriate to apply the technique of principal component analysis. We have applied this technique of data reduction as an intermediate step obtaining, three new uncorrelated variables (dimensions) between each 
other, which, later on, will be used to perform differential comparative analysis by taking into account the personal and professional characteristics of the interviewed subjects.

In the case of dimension 1 the first eight items (apart from 11) are shown to highly saturate that factor, so it is considered a measure of the degree of interactivity and planning in lectures of all the teachers interviewed. Dimension 2 indicates the degree to which teachers use new Information Technologies (NICT) in their classrooms and promote a foreign language, which is related to the acquisition and development of generic skills. Finally, it can be stated that dimension 3 only corresponds to item 7 , which concerns the extent to which teachers interviewed organize classroom discussions on topics related to the subjects being treated.

The next step is testing Anova on each of these three dimensions or new variables in order to study whether the answers are the same for the different groups (p-value <0.05) or if there is a common viewpoint. On the basis of the results obtained with the ANOVA test ${ }^{2}$, dimension 1 (interactivity and lesson planning) show relevant differences when the gender variable is considered. It enhances the high percentage of women (83\%) compared to men (65\%) who report that their classes are increasingly more interactive. The major involvement of women is also evident in all other questions, except question 5, where the results obtained by both sexes are broadly similar.

In the case of dimension 2 (use of NICT and use of foreign language), different average results are observed by taking into account the professional features (employment situation, professional status and experience in the teaching practice). Regarding the employment situation and teaching experience, the highest percentage of teachers who agree or strongly agree with question 10 (Promoting the use of a foreign language) are the civil servants and teachers who are in the range of 20-30 years or have over 30 years of teaching experience.

According to professional status (rank or work category), it can be observed that lecturers with greater stability (Full Professor and Associate Professor) are the ones using NCIT to a greater extent during the development of classes, which is also confirmed from the analysis of the labor situation as $88 \%$ of teachers who are civil servants agree or strongly agree with question 9 (table 3). With regard to the other employment categories the Assistant Professor position can be highlighted, as $85 \%$ of teachers from this group reveal they habitually use these resources in the classroom.

\section{Conclusions}

This paper analyzes the implications of the Bologna Process concerning two specific issues: the perception of teachers of their new role and its consequences, and to what extent the

\footnotetext{
2 Tests for equality of means-One way ANOVA have not been shown due to space limitations.
} 
adaptation to Bologna has brought about major or minor changes in the teaching methodology.

On the one hand, there is unanimous opinion that the new role of the University teacher (more committed to the ongoing assessment and interactive classes, using NICT actively, fostering tutorials, etc.) requires greater dedication than the traditional one which should be taken into consideration by the university system. Attention should be drawn to the staffs' concerns to have a reliable and rigorous system to evaluate their teaching, in line with the assessment of the research activity. The great importance given to research can prejudice lecturers who invest more effort in improving the quality and effectiveness of their classes.

Regarding certain changes in the way of teaching, it is important to highlight that the teacher attaches great importance to the development of his/her own material for students as well as the increased use of NICT. As expected, the University is moving in this direction at the same pace as society. It can be concluded that teachers are aware that in the new context or educational setting, content is as important as procedure when transmitting knowledge to students.

In relation to professional characteristics, the teachers interviewed with 10 to 20 years of experience are those incorporating more changes in teaching skills. On the other hand, this research shows that the teachers interviewed with less stable profiles in the workplace and who are less experienced (Temporary staff and Assistants) believe that research, as well as lack of resources and time, prevent them from devoting more time to their teaching. In terms of gender, women feel to a greater extent the need for training and for involvement in order to adapt to the challenges of the new teaching model promoted by EESS and the new role that university teachers must acquire.

Finally, it is important to note the fact that the use of English in the classroom is severely limited in the Spanish university education system. It is absolutely necessary to make progress in this issue and to attempt to solve it with the necessary measures so that the Spanish University may have a significant presence in the world.

\section{References}

Ariza, T., Quevedo-Blasco, R. \& Buela-Casal, G. (2014). Satisfaction of Social and Legal Sciences teachers with the introduction of the European Higher Education Area. The European Journal of Psychology Applied to Legal Context, doi: 10.5093/ejpalc2014a2.

Cabello, J. \& Antón, P. (2005). Conversaciones con el profesorado. Un estudio en cuatro universidades españolas sobre el espacio europeo y el uso de las TIC. Revista de Educación, 337, 149-167.

Cavero, J.A., Reig, J. and Pérez A. (2014). Studies in business administration in the European higher education area: a comparative analysis in Europe. Innovations in Education and Teaching International, doi: 10.1080/14703297.2014.928228. 
Fernández Díaz, M.J., Carballo Santaolalla, R. \& Galán González, A. (2010). Faculty attitudes and training needs to respond the new European Higher Education challenges. Higher Education, doi: 10.1007/s10734-009-9282-1.

Fernández-Sainz, A., García-Merino, J.D. \& Urionabarrenetxea, S. (2015), Has the Bologna Process been worthwhile? An analysis of the Learning Society-Adapted Outcome Index through quantile regression. Studies in Higher Education, doi:10.1080/03075079.2014.988703A.

Linblom-Ylänne, S. Trigwell K., Negvi, A. \& Ashwin P. (2007). How approaches to teaching are affected by discipline and teaching context. Studies in Higher Education, 31 (3), 285-298.

Macfarlane, B. (2011). Lecturers as intellectual leaders: formation, identity and role. Studies in Higher Education, 36 (1), 57-73.

Quevedo-Blasco, R, Ariza, T. and Buela-Casal, G. (2015), Asssesment of science teachers'satisfaction with the adaptation to the European Higher Education Area. Educacion XXI, 18 (1), 45-70.

Trilling, B. \& Fadel, C.(2009). 21st. century skills. Learning for life in our times. San Francisco: Jossey-Bass. 